\title{
Diseño de un modelo de franquicias en la industria de comestibles de pan de arroz
}

\section{Design of a franchise model in the rice bread grocery industry}

\author{
Projeto de um modelo de franquia no setor de pães de arroz \\ Monroy Tineo Neidy Marcela ${ }^{1}$ y Ayza Yamir Urbina Angarita ${ }^{2}$ \\ ${ }^{1}$ Ingeniera Agroindustrial Universidad de los Llanos e \\ ${ }^{2}$ Ingeniera Agroindustrial, MSc. Docente Universidad de los Llanos \\ aurbina@unillanos.edu.co
}

Recibido 27 de agosto 2019, Aceptado 12 de marzo 2020

\section{RESUMEN}

La industria del pan de arroz ha consolidado un crecimiento importante en los últimos años, siendo un producto típico del departamento del Meta y en la búsqueda por su expansión hacia mercados nacionales se plantean estrategias de crecimiento en las pequeñas y medianas empresas que producen estos productos; para tal efecto en el presente proyecto se busca diseñar un modelo de franquicias para la Industria de Comestibles de pan de arroz, especializada en esta producción, ubicada en el municipio de Restrepo, Meta, Colombia que le permita expandir sus unidades de negocio y lograr el fortalecimiento de su marca, mediante la creación de manuales operativos que logren estandarizar todos sus procesos. Se determinó que la estructura del sistema de franquicias más adecuada para esta empresa es la de producción, siendo el franquiciador que provee todos los productos al franquiciado, que pueden ser distribuidos de manera ultra congelada y empacada al vacío, listo para hornear y consumir; de esta manera, se controla la calidad de los procesos de elaboración, no se afecta la imagen de la marca por la pérdida de las características propias de los productos.

Palabras clave: Pan de arroz, franquicia, manuales operativos. 


\section{ABSTRACT}

The rice bread industry has consolidated significant growth in recent years, being a typical product of the Meta department and in the search for its expansion into national markets, growth strategies are proposed in the small and medium-sized companies that produce these products; For this purpose, the present project seeks to design a franchise model for the Rice Bread Food Industry, specialized in this production, located in the municipality of Restrepo, Meta, Colombia that allows it to expand its business units and achieve the Strengthening your brand by creating operating manuals that standardize all your processes. It was determined that the structure of the franchise system most suitable for this company is that of production, being the franchisor that provides all the products to the franchisee, which can be distributed ultra frozen and vacuum packed, ready to bake and consume; in this way, the quality of the manufacturing processes is controlled, the brand image is not affected by the loss of the characteristics of the products.

Keywords: Rice bread, franchise, operating manuals.

\section{RESUMO}

A indústria do pão de arroz consolidou um crescimento significativo nos últimos anos, sendo um produto típico do departamento Meta e na busca por sua expansão nos mercados nacionais, estratégias de crescimento são propostas nas pequenas e médias empresas que produzem esses produtos; Para esse fim, o presente projeto busca projetar um modelo de franquia para a Indústria de Alimentos para Pão de Arroz, especializada nessa produção, localizada no município de Restrepo, Meta, Colômbia, que permite expandir suas unidades de negócios e alcançar Fortalecendo sua marca, criando manuais operacionais que padronizam todos os seus processos. Foi determinado que a estrutura do sistema de franquias mais adequada para essa empresa é a estrutura de produção, sendo o franqueador que fornece todos os produtos ao franqueado, que podem ser distribuídos ultracongelados e embalados a vácuo, prontos para assar e consumir; dessa forma, 
a qualidade dos processos de fabricação é controlada, a imagem da marca não é afetada pela perda das características dos produtos.

Palavras-chave: Pão de arroz, franquia, manuais de operação.

\section{INTRODUCCIÓN}

El modelo de franquicias es un sistema celebrado entre dos partes el franquiciador cede a sus franquiciados, que es la otra parte, los derechos de uso y comercialización de su marca, bajo un concepto de desarrollo de negocio que ha sido creado por él mismo (Alcalzar 2011), esto, a cambio de una contra-prestación económica que contiene términos y condiciones pactados mediante un contrato. La principal característica de este sistema es el bajo riesgo de inversión al que se expone el franquiciado y la capacidad de rápido crecimiento y expansión del franquiciador.

En Colombia, la implementación y comercialización de franquicias ha aumentado en los últimos 12 años en cifras significativas, siendo considerado por la asociación internacional de franquicias como el tercer país con mayor potencial de crecimiento después de India e Indonesia (Amorocho, 2019). En estos términos, el sector que muestra más unidades franquiciadas es el alimenticio, pues diferentes empresas incorporan este modelo de negocio dentro de sus planes de expansión; es así como la industria colombiana de comestibles entre ellas las productoras de pan de arroz, un bocado típico de la región de los Llanos Orientales, busca adaptarse a este tipo de sistema para diversificar su mercado a nivel nacional y no solamente regional.

La industria del pan de arroz es una cadena productiva que mueve alrededor de $\$ 7.526$ millones de pesos cada año, impulsando el desarrollo económico y forjando la cultura y el empleo en el departamento del Meta, siendo los principales productores los municipios de San Martin, Villavicencio y Restrepo, con una cantidad diaria de 14.500 paquetes. Los principales mercados de este producto son a nivel a regional, sin embargo, ha dado inicio a una expansión hacia las principales ciudades del país mediante diferentes estrategias Gobernación del Meta, (2016). Es allí donde la franquicia es importancia, pues como un modelo flexible de negocio, 
permite al franquiciante, establecer una amplia red comercial, proporcionando un posicionamiento más acelerado en el mercado y reforzando la identidad de su marca, además de la posibilidad de brindar un soporte permanente de la organización sobre su imagen, operatividad, marketing y publicidad, a la vez que asegura sus operaciones, puesto que por ser un modelo de negocio que comprobado ser exitoso, tiene un menor riesgo de fracaso, pues "el $90 \%$ de los de los establecimientos comerciales franquiciados tienen la capacidad de sobrevivir por más de cinco años" (Jaramillo, 2016).

En Colombia, el crecimiento del modelo de franquicias ha mostrado gran auge en los últimos años, de acuerdo a la Cámara Colombiana de Franquicias (Colfranquicias) (CCB, 2017). en los últimos años este tipo de negocios ha presentado un incremento sostenido, siendo del 7\% para el año 2015 y del 29,7\% al cerrar el 2017, esta alza se da debido a las condiciones de la economía y las ventajas competitivas del mercado nacional, pues se constituye como el tercer país con la mayor potencialidad de crecimiento en el mundo después de india e Indonesia y el cuarto en número de franquicias a nivel latinoamericano. El número de unidades franquiciadas en el país alcanzo un total de 506 marcas nacionales e internacionales con alrededor de 12.900 empresas, de las cuales el $37 \%$ son pertenecientes al sector gastronómico siendo este el de mayor participación con alrededor de 188 empresas (CCB, 2017).

Ante la notable expansión de franquicias en el país se creó la Norma Técnica Colombiana 5813, la cual tiene como objeto de establecer de manera general los requisitos básicos de una franquicia, debido a que se hace necesario que el franquiciante estructure el formato de franquicias, estandarice y documente sus procesos administrativos y operativos, definiendo los lineamientos legales entre las partes interesadas (ICONTEC, 2010).

\section{HISTORIA DE LAS FRANQUICIAS}

Buscando en la historia, el término franquicia surge en Francia en la edad media y significaba la concesión de derechos por parte de los gobernantes para autorizar a 
sus subordinados a realizar labores de pesca y caza en determinados lugares. Sin embargo, el sistema de franquicias como tal surge en Estados Unidos a mediados del siglo XIX después de la guerra civil, cuando Isaac Singer, dueño de la compañía fabricante de máquinas de coser Singer \& Co. establece el sistema de franquicias para que sus máquinas se pudieran distribuir y comercializar en todo el mundo. En adelante surgen otras empresas que empiezan a adoptar la misma estrategia como el caso de General Motors, Ford, Coca Cola, Texaco y Standard Oíl, pero el auge real de las franquicias comenzó después de la segunda guerra mundial cuando se reactivó la producción civil y las empresas se vieron en la necesidad de expandir sus mercados y fue así como surgieron grandes casos productoras de alimentos de comidas rápidas y supermercados de tal forma que para el año 1960 se crea la IFA (Internacional Franchise Association) con el fin de garantizar que todos su asociados estén regidos por un código de ética. Para el año 1988 en EEUU existían aproximadamente medio millón de negocios franquiciado y para el año 2018 se estima una cantidad de 759.000 establecimientos franquiciado (Mosquera, 2010).

Por su parte la franquicia en Colombia tuvo sus inicios hacia el año 1980 con la llegada de la cadena de establecimientos estadounidense de comidas rápidas Burger King, seguido de compañías como Kokoriko, Frisby y Presto. Hacia los años 90 continua el crecimiento de este tipo de negocios, principalmente del sector gastronómico, surgiendo franquicias de compañías como Mc Donald, Crepes and Waffles, Subway y Dunkin Donuts y Sándwich Cubano (Rodríguez y Mora, 2013).

\section{¿QUÉ ES UNA FRANQUICIA?}

Se pueden encontrar diversas definiciones de franquicia, según diferentes órganos nacionales e internacionales que se han creado alrededor del mundo con el fin de garantizar la protección a la industria de las franquicias; dentro de los más importantes se encuentran la Asociación Internacional de Franquicias (IFA) y La federación europea de la franquicia (FEF) (Mosquera 2010). La Asociación Internacional de Franquicias (IFA) es la organización más antigua y más grande que representa a las franquicias en todo el mundo y define la franquicia simplemente como un método para expandir un negocio y distribuir bienes y servicios a través de 
una relación de licencia, en la cual los franquiciadores no solo especifican los productos y servicios que ofrecerán los franquiciados, sino que también les proporcionan un sistema operativo, una marca y soporte (Restrepo y Barrera, 2018).

Entre tanto, la Federación Europea de la Franquicia (FEF) define la franquicia como: Un sistema de comercialización de productos y/o servicios y/o tecnología, basado en la colaboración estrecha y continuada entre empresa legal y financieramente distinta e independiente, el franquiciador y sus franquiciados individuales, por el cual el franquiciador concede a sus franquiciados individuales el derecho e impone la obligación de llevar un negocio de conformidad con el concepto del franquiciador. Este derecho faculta y obliga al franquiciado individual, a cambio de una contraprestación económica, directa o indirecta, a utilizar el nombre comercial y/o la marca de productos y/o servicios, el know-how, los métodos técnicos y de negocio, los procedimientos, y otros derechos de propiedad industrial $y / 0$ intelectual del franquiciador, apoyado en la prestación continua de asistencia comercial y técnica, dentro del marco y por la duración del contrato de franquicia escrito, pactado entre las partes a tal efecto (Restrepo y Barrera, 2018).

Según Arredondo, (2003) en cualquier definición, surgen puntos en común alrededor del significado de una franquicia, tales como: relación entre ambas partes que se materializa mediante una licencia o contrato; el franquiciador debe transmitir al franquiciado la operatividad de su negocio, conocido también como know-how o saber hacer; el franquiciador debe ofrecer al franquiciado constante asistencia técnica y comercial; el franquiciado debe pagar un canon a cambio de la explotación de la marca del franquiciante.

En términos generales, un sistema de franquicias se compone de dos partes interdependientes, un franquiciador, el cual cede el derecho a utilizar su marca a un franquiciante, a cambio de una compensación monetaria, la cual se define mediante un contrato en el que además se estipulan las obligaciones, derechos y límites de las partes involucradas. Cabe aclarar que una franquicia no es sinónimo de distribuidora, comercializadora, ni tampoco es una sociedad. 


\section{TIPOS DE FRANQUICIAS}

De acuerdo a su actividad, ubicación y relación entre franquiciador y franquiciado, las franquicias se pueden clasificar de la siguiente manera: industrial, de distribución, de producción, de servicios y mixta. Para efectos de este caso se realizó con enfoque en las franquicias de acuerdo con su actividad comercial, puesto que la Industria de Comestibles de pan de arroz se va expandir bajo un modelo de franquicia de producción. En la de tipo industrial: el franquiciador como el franquiciado fabrican los productos, el primero, además de ceder el derecho de comercializarlos entrega su conocimiento de cómo se elaboran los mismos, adicionalmente debe facilitar los procedimientos administrativos, de gestión y de ventas. La de producción: es un contrato en el cual el franquiciador es quien fabrica todos los productos y los vende al franquiciado, asegurando así la venta de su producción. La de distribución: se da cuando el franquiciador actúa como una central de compras, adquiriendo todos los productos para entregar al franquiciado, los cuales son fabricados por empresas externas. La de servicios: son las que se ofrece un conjunto de servicios mediante una metodología que ha sido otorgada por el franquiciador, en este caso se acrecienta la importancia de transmitir un buen conocimiento. Por últimos la mixta es aquel tipo de franquicia en el que se articula el modelo de negocio de productos y servicios (Silva, 2003).

\section{VENTAJAS Y DESVENTAJAS DE UNA FRANQUICIA}

El sistema de franquicias como modelo comercial tiene prometedoras ventajas de rentabilidad y éxito, sin embargo, se pueden presentar inconvenientes que dependen en gran parte se acuerden las obligaciones estipuladas entre las partes. Una ventaja es que el franquiciador tendrá una rápida expansión con menores costos de inversión, obteniendo mayor rentabilidad, a su vez se refuerza la identidad de su marca y diversifica sus ingresos al recibir un pago de regalías; mientras que el franquiciado se beneficia de la experiencia, imagen, publicidad y marketing del franquiciante, reduciendo el riesgo de fracaso y aprovechando la asistencia técnica proporcionada. Una de las desventajas es no tener una buena comunicación entre la partes o desacuerdos, a la hora de realizar la gestión de procesos administrativos, 
aunque los franquiciados son independientes, tienen poco control y libertad sobre los métodos de operación en la empresa, lo cual es un riesgo por el mal uso de la marca, sin embargo, estas consideraciones deben ser estipuladas mediante el contrato legal que firman las partes interesadas (PROMPERÚ, 2012).

\section{¿COMO FRANQUICIAR UNA EMPRESA?}

Inicialmente el empresario que decide franquiciar su marca debe tener previo conocimiento de cómo funciona este sistema, las leyes que lo regulan y sus condiciones y características, por lo que debe respaldarse de un consultor especializado en el tema. Una vez informado, le corresponde determinar las posibilidades de convertirse en franquiciante, lo que incluye el cumplimiento de los siguientes aspectos fundamentales: 1 . Ser marca reconocida y que se encuentre debidamente registrada. 2. Ser negocio sea atractivo, rentable y le dé seguridad de éxito a los franquiciados potenciales. 3. Ser un modelo de negocio fácil de transmitir y replicar mediante el conocimiento (Know-how). 4. Tener un producto excelente, que sea atractivo para los clientes y que cuente con un mercado potencial y en expansión (Ramírez, 2017).

Luego de determinar la preparación como empresario para convertirse en franquiciador se deben realizar la definición del modelo de franquicia, esto es, el análisis profundo de todos los aspectos que lo rodean, desde estructura, valores, posicionamiento, clientes, hasta el análisis global de producción y servicios, análisis financiero, viabilidad económica y estudios de mercado; esto con la finalidad de establecer la estructura central del franquiciador para definir su capacidad de soporte a todo el sistema de franquicias. Una vez definido el modelo de negocio franquiciable se procede a completar el sistema de franquicias (Figura 1) el cual se complementa con las bases legales y jurídicas, la documentación correspondiente a manuales operativos y la estrategia para la expansión de la red (CEF, consultado 2018). 


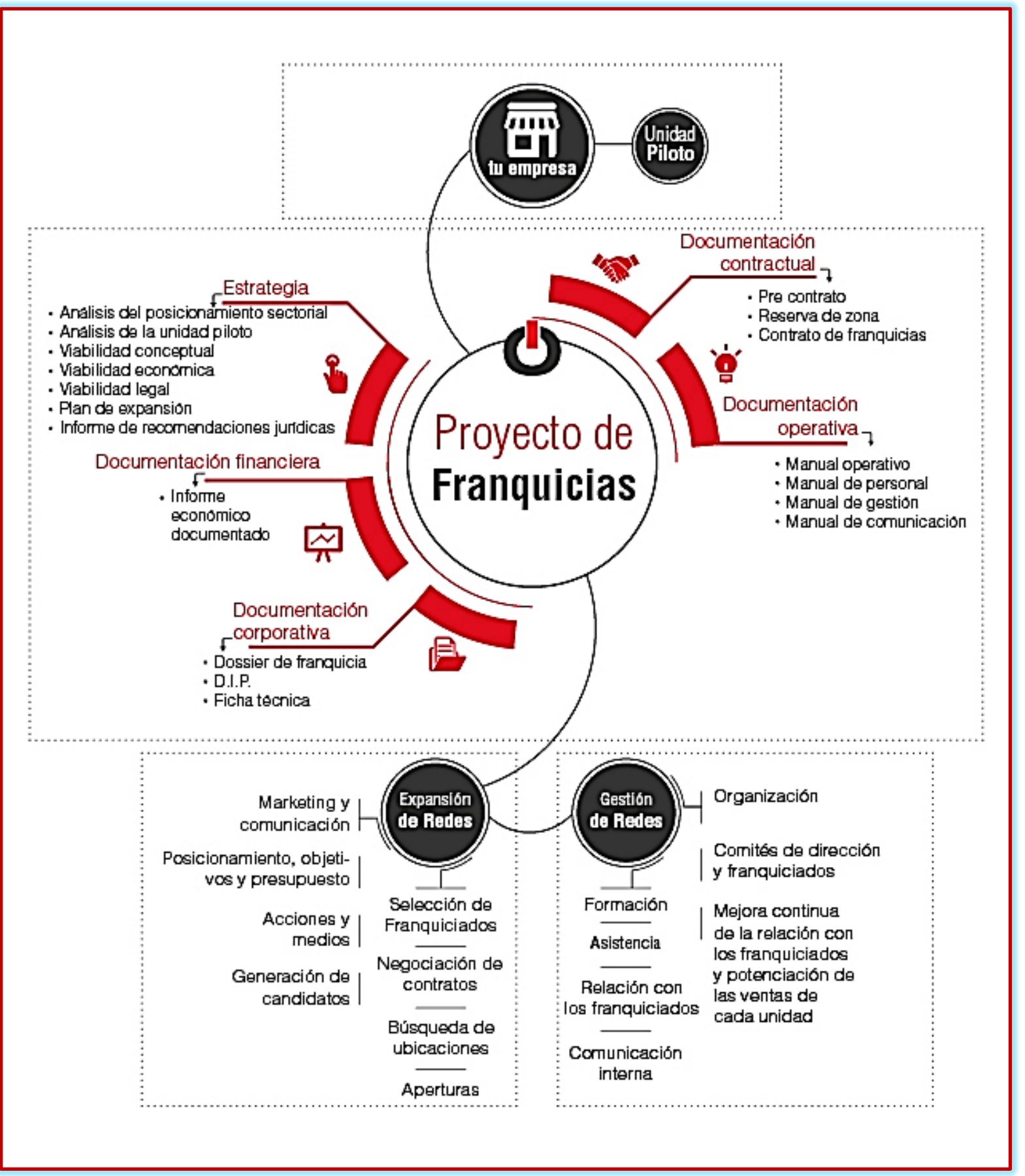

Figura 1. Sistema de franquicia. Fuente: (CEF), consultado el 2 de agosto 2018

\section{DOCUMENTACIÓN JURÍDICA O CONTRACTUAL}

Crear una red de franquicias abarca tres partes fundamentales: Organización del modelo de franquicia, desarrollo de las bases documentales (informativas, operativas, contractuales) y diseñar las estrategias de expansión. 
Los aspectos legales de una empresa son determinantes para su correcto funcionamiento, es por ello que al crear una red de franquicias se debe estructurar un contrato que es el elemento base para regular los derechos y deberes de franquiciador y franquiciados, en ocasiones también se diseña un precontrato. Este tipo de documento no tiene una estructura definida, pues esta depende del país en donde se vaya a implementar y la normatividad que regule este tipo de contratos. En Colombia el contrato de franquicia no se encuentra regulado ni definido por la normatividad interna, lo que lo convierte en un contrato atípico, sin embargo existe normatividad que puede ser aplicable, estos contratos se pueden regir por la ley mercantil, puesto que el objeto del contrato de franquicia está relacionado con las actividades señaladas en el artículo 20 del Código de Comercio como actividades de tipo mercantil, por lo cual le son aplicables las disposiciones generales señaladas en este código para los contratos mercantiles (Loaiza, 2012).

Por otra parte algunos empresarios y organizaciones como la cámara de comercio de Bogotá han creado una serie de herramientas para fomentar el modelo de franquicia en nuestro país, de este tipo de iniciativas surgió la Norma Técnica Colombiana 5813, desarrollada por el organismo nacional de normalización ICONTEC; teniendo como objeto el establecimiento de los requisitos básicos, así como las buenas prácticas comerciales, que las partes interesadas deben observar en la relación pre-contractual, contractual y post contractual de una franquicia. En esta Norma se consideran cuatro elementos fundamentales, objetivo, términos y definiciones, requisitos para franquiciar una marca y los elementos esenciales de un contrato, estos últimos son: modelo de negocio franquiciado, condiciones de uso de licencia, régimen de asistencia técnica y vigencia y territorio sobre el cual se concede el derecho de uso de la franquicia (CC, 1971; ICONTEC, 2010).

\section{DOCUMENTACIÓN INFORMATIVA O CORPORATIVA}

La documentación informativa de una franquicia se hace referencia al dossier, que no es más que un documento escrito que contiene información básica de un tema, en este caso, el dossier informativo es una herramienta de marketing y ventas, dirigida a los posibles franquiciatarios, en la que se exponen aspectos básicos del 
modelo de negocio de una forma precisa y atractiva para el futuro inversor. Un dossier de franquicia no tiene una estructura definida, pues el diseño del mismo es propio de cada empresa; la clave de su elaboración es el enfoque de transmitir la información de interés para el público al que va dirigido. Sin embargo, es vital la inclusión de los siguientes datos: 1- Historia de la organización, misión, visión, valores corporativos. Descripción de la actividad empresarial, productos ofrecidos, características, imágenes, distintivos de marca. 3- Ventajas competitivas del negocio 4- Cifras de crecimiento que revelen el posicionamiento de la marca en el mercado 5-Información práctica sobre como adquirir la franquicia, beneficios, ventajas. 6-Desglose de inversión y 7- Finalmente, datos de contacto para recibir mayor información (ICONTEC, 2015).

\section{DOCUMENTACIÓN OPERATIVA}

Antes de hablar sobre la documentación operativa se debe mencionar el concepto de Know-how o saber-hacer, de acuerdo con la NTC 5813 es un conjunto o sistema de conocimientos, experiencia y/o prácticas que conforman el saber hacer del Franquiciante, es la base que le ha permitido alcanzar el éxito y que debe transmitirse al franquiciado en forma de manuales que contribuyen a la homogenización de toda la red de franquiciatarios (ICONTEC, 2015).

Manual técnico. Constituye la base fundamental de los manuales operativos, en él se consigna información respectiva a los productos, fichas técnicas, procesos, proveedores, equipos, procedimientos de limpieza y desinfección, buenas prácticas de manufactura, sistemas de gestión de calidad e instalaciones de los locales.

Manual de estructura organizativa y personal. Incluye el organigrama de la central de franquicias, sus funciones y así mismo define la de sus franquiciados, obligaciones, responsabilidades, número de empleados, perfil de los colaboradores, desempeño y normas en el puesto de trabajo.

Manual de imagen corporativa y gestión comercial. Mediante este manual se realizará la identidad visual de la marca, con aspectos claves como logotipo, colores, mobiliario, tipografía y elementos decorativos en general. Además, 
establece los lineamientos para atender quejas y reclamos y brinda herramientas de publicidad y promociones, política de precios, técnicas de venta, de motivación y fidelización para el cliente (ICONTEC, 2015).

\section{EXPANSIÓN DEL SISTEMA DE FRANQUICIA}

Una vez se ha definido el concepto de negocio se deben poner en marcha las estrategias para la comercialización de la franquicia, pues el éxito de las mismas se fundamenta en su capacidad de desarrollo, para ello se deben tener en cuenta los siguientes criterios: 1-Conocer las limitaciones y capacidad de respuesta de la central franquiciadora, por ejemplo, si es una franquicia de producción de saber cuál es su capacidad instalada en planta para determinar cuántas unidades franquiciables puede solventar. 2- Posteriormente se debe definir a que lugares se quiere llegar con la franquicia, estudios de mercado, aclarar el tema de exclusividad de zona que debe garantizarse. 3- Luego de establecer los anteriores criterios se procede con el plan de expansión, mediante el uso de diferentes herramientas como medios de comunicación, asistencia a ferias y congresos de franquicias, medios de comunicación y campañas de marketing en las zonas de expansión definidas con anterioridad con las cuales se refuerza la imagen corporativa de la marca y se pretende la captación de los potenciales franquiciados (Mosquera, 2010)

\section{LA FRANQUICIA EN COLOMBIA}

Las franquicias se han consolidado en Colombia en los últimos años como una gran estructura empresarial, ya que son una muy buena opción para la expansión de una marca, tienen alta permanencia en el tiempo y son una fuente de generación de empleo.

Para el año 2015 el número de franquicias en el país alcanzaba 384 marcas, en el 2016 aumento a 443 y en lo corrido del año 2018 se han registrado 506 empresas consolidadas mediante este modelo, según, presidente de la junta directiva de Colfranquicias 294 son nacionales y 212 extranjeras, siendo el sector gastronómico el que encabeza la lista con un total de 188 , seguido por los sectores de servicio (86) y moda (82); cifras que llevan al país a ocupar el cuarto lugar de Latinoamérica 
en cantidad de franquicias después Brasil, México y Argentina. Además, por las condiciones del mercado, Colombia presenta un crecimiento económico favorable, constituyéndose como el tercer país con la mayor potencialidad de crecimiento de las franquicias a nivel mundial según un estudio realizado por la International Franchise Association (IFA), el cual fue presentado en el marco del World Franchise Council (WFC) que se reunió en Moscú a finales de mayo del 2017, por lo que se espera seguir creciendo de forma exponencial con la llegada de marcas extranjeras y nuevos emprendedores nacionales (Jaramillo, 2018).

\section{LA FRANQUICIA EN EL META}

Este modelo de negocio ha mostrado su expansión en las grandes urbes del país como Bogotá, Medellín y Valle del Cauca, sin embargo el departamento del Meta y su capital Villavicencio tienen grandes ventajas como su cercanía a la capital, el dinamismo de su economía y crecimiento de sus mercados, que se ven reflejados en gran parte en la apertura de diferentes centros comerciales que permiten la llegada de múltiples marcas nacionales y extranjeras, en los últimos 5 años han llegado tres nuevos complejos comerciales, Único Outlet en el año 2013, Viva Villavicencio en 2014 y Primavera urbana en el año 2016, con alrededor de 300 marcas diferentes que promueven la expansión del sistema de franquicias en la región.

\section{FRANQUICIA PARA UNA INDUSTRIA DE PAN DE ARROZ}

De allí surge la importancia del diseño del modelo de franquicia y la documentación de los manuales para una Industria de Comestibles de pan de arroz, orientado a garantizar que la franquicia opera con altos niveles de calidad, cumpliendo con los requisitos establecidos por la norma internacional ISO 9001 y otorgando así al franquiciante una herramienta que brinda un valor agregado a todas las operaciones de su negocio y que además le permite una rápida expansión, posicionamiento de marca en el mercado nacional, mayor cobertura de mercados y el aprovechamiento de economías de escala (INCONTEC, 2015). 
El pan de arroz es un snack horneado que se elabora a partir de la mezcla de arroz, cuajada, levadura, margarina, azúcar y sal, también conocido como rosquitas o rosquillas de arroz y queso, su presentación clásica es en forma de aros crujientes, sin embargo, también se encuentra como pan de arroz blando (Figura 2).

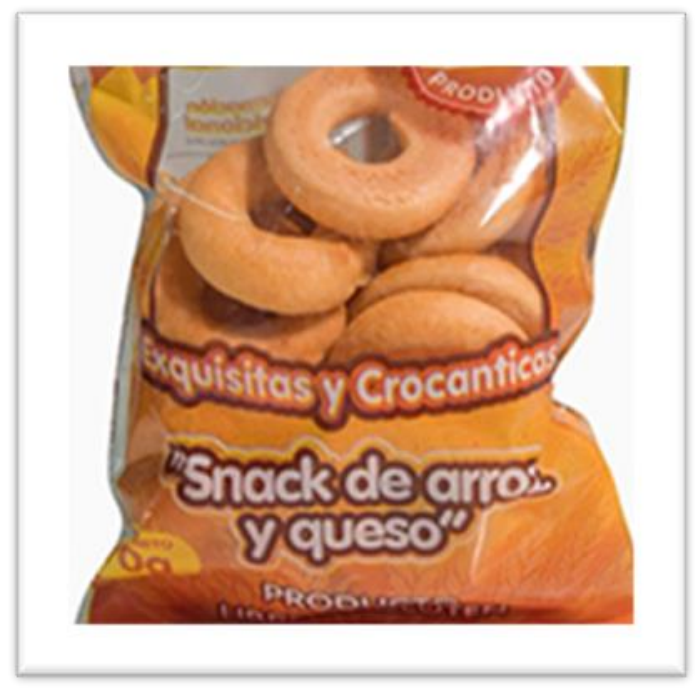

Figura 2. Pan de arroz, producto horneado producido en el departamento del Meta Las empresas que elabora este producto deben contar con notificación sanitaria para sus, expedida por el INVIMA, mediante la cual la empresa tiene la facultad para elaborar, comercializar, importar, exportar, envasar, procesar, y vender sus productos, los cuales se encuentran categorizados como de bajo riesgo sanitario desde el punto de vista microbiológico (MSPS, 2015), de esta manera las empresas cumplen su misión como y contribuyen al bienestar de las personas, produciendo y comercializando productos de máxima calidad a través de las Buenas Prácticas de Manufactura (BPM), rigiéndose mediante la resolución 2674 (MSPS, 2013), mediante la cual se verifican y se garantizan las condiciones higiénico sanitarias del entorno y las etapas de producción, procesamiento, empaque, almacenamiento, transporte y comercialización de los productos, para que estas no constituyan un factor de riesgo de contaminación de los mismos.

De igual manera estas empresas deben contar con la documentación requerida por la ISO 9001 en los referente al sistema de gestión de calidad, referente al manual de calidad, política y objetivos de calidad y los procedimientos y registros pertinentes 
para obtener una consistencia de las operaciones de la organización, proporcionar claridad sobre los procesos y por ende conseguir un sistema de gestión funcional, que además le permite ofrecer su modelo de negocio como un sistema de franquicias (ICONTEC, 2015).

Se diseñó un modelo de franquicias para una Industria de comestibles de pan de arroz, mediante una metodología, que fue descrita anteriormente. En este proceso se recopiló la información y definición del tipo de franquicia, desarrollando los manuales operativos que le permiten transmitir el saber-hacer como compañía a sus futuros franquiciados. Las fuentes de información para realizar este trabajo, pues fueron primarias tomadas de entrevistas con personal administrativo y operativo, con la finalidad de diagnosticar los aspectos inherentes a su operatividad, determinando las características actuales de su modelo de negocio, de esta manera, se procedió con el diseño del sistema de franquicia apropiado para esta organización.

De acuerdo con el diagnóstico la franquicia seleccionada fue la de producción, siendo esta industria el franquiciador que fabrica la mayor parte de los productos y el franquiciado se encarga de la distribución, comercialización, y elaboración de algunos productos en específico, teniendo como garantía la calidad e imagen de la marca ante el mercado. De esta forma, se definió: ¿qué ofrece la empresa productora de pan de arroz como franquiciador?, ¿cómo lo ofrece? y ¿qué se requiere por parte del futuro franquiciado?, es decir, misión y visión como franquicia, objetivos estratégicos del sistema, productos de la empresa, propuesta de valor y documentación de los requisitos y formatos necesarios para los procesos de solicitud, evaluación y selección de franquiciados, reuniendo los anteriores parámetros en un manual denominado manual de franquicias, que además recopila los siguientes manuales:

Manual de operaciones: Es uno de los manuales que constituyen la base fundamental del sistema de franquicias, pues en él se plasmó la información correspondiente a instalaciones, equipos, productos, procesos de elaboración y 
procedimientos operativos estándares de calidad, que incluye el plan de saneamiento básico y sus programas prerrequisitos.

Manual de administración y recursos humanos: El manual de recursos humanos presenta la estructura organizativa de las franquicias de la empresa productora pan de arroz y ofrece al franquiciado los lineamientos para selección y contratación de personal idóneo, perfiles de puesto y el reglamento interno de trabajo. Por su parte, el manual administrativo, incluye información para una gestión adecuada respecto a los procesos de aprovisionamiento de insumos y materias primas, control de inventarios, administración de caja, manejo de quejas y reclamos, procesos de venta y política de precios.

Manual de imagen corporativa: En él se definen y describen los lineamientos para el buen uso de los componentes visuales de la marca empresa productora pan de arroz como logotipo, tipografía y uniformes, estableciendo la homogeneidad grafica de la misma.

Manual jurídico: Define la relación del acuerdo pactado entre empresa productora pan de arroz en calidad de franquiciador y su franquiciado, estableciendo pautas anteriores a la firma de la documentación, derechos y obligaciones de las partes, condiciones de pago, reserva, confidencialidad, duración y finalización del contrato. Este manual se desarrolló bajo la asesoría de un profesional de derecho de la empresa productora pan de arroz.

\section{CONCLUSIONES}

Los manuales de franquicia son una herramienta que permiten organizar y controlar la información de una o más unidades administrativas de cualquier industria, independientemente de su actividad comercial, contribuyendo a la estandarización de los métodos de trabajo, mediante documentos que manejan información formal y sirven de apoyo para la mejora continua de los procesos, estableciendo controles administrativos, derechos y deberes de las partes y evitando la implementación de procedimientos incorrectos de parte del franquiciante y del franquiciado, de tal forma 
que deben ser redactados de forma clara y precisa para que puedan ser comprendidos y adaptados por los franquiciados.

Los manuales de franquicia son únicos y exclusivos para cada industria, y no existe una normatividad que regule su elaboración, su contenido es el resultado del análisis que establece cada organización para definir cómo va a franquiciar su negocio.

Se determinó que la estructura del sistema de franquicias más adecuada para la empresa productora pan de arroz es la de producción, en la que el franquiciador provee de todos sus productos al franquiciado, gracias a que, en su amplio portafolio, la mayor parte de productos son empaquetados y su producto bandera, el pan de arroz, puede ser distribuido ultra congelado y empacado al vacío, listo para hornear y consumir; de esta manera, se controla la calidad de los procesos de elaboración, no se afecta la imagen de la marca por la pérdida de las características propias de los productos y se lleva un registro de las quejas o reclamos presentadas por el consumidor final. No obstante, es necesario propiciar toda la información correspondiente a los procesos operativos a través de los manuales de franquicias.

La documentación contractual es única para cada unidad franquiciada y debe modificarse en función de criterios como tiempo de duración del contrato, exclusividad territorial a otorgar, número de franquicias que posea el franquiciado y ubicación de la misma.

La elaboración de este manual permitió reunir y aportar información general de interés para las Mipymes agroindustriales que busquen la formulación de proyectos orientados a consolidar su negocio mediante el sistema de franquicias; destacando sus principales características, impulsando la actualización y aplicación de nuevos procedimientos, la introducción de nuevos productos, la vigilancia de los procesos en el marco de las Buenas Prácticas de Manufactura; permitiendo una mejor inserción de las empresas en los mercados locales y nacionales, gracias a que la integración de estos aspectos a lo largo de toda la cadena de producción y abastecimiento, el manejo adecuado de la información (comunicación entre áreas o 
eslabones de cadenas), la observación de los mercados y la adecuada planificación de agroindustrias permite no sólo el avance del sector sino la consolidación de las empresas, el crecimiento y posición de su marca, garantizado la inocuidad de sus productos y la calidad de sus servicios.

El diseño de este modelo de franquicias de la empresa productora pan de arroz permitió la aplicación de diferentes áreas de conocimiento del plan de estudios adquiridos durante la formación como Ingeniero Agroindustrial, entre las cuales se destacan aseguramiento de la calidad, administración de la producción, formulación y evaluación de proyectos, administración y mercadeo agroindustrial.

\section{RECOMENDACIONES}

Lo manuales de franquicia son documentos que están sujetos a cambios constantes por modificaciones o actualizaciones en la marca o procesos, por lo cual se recomienda revisar periódicamente. Los manuales operativos son una herramienta para asegurar la calidad de los productos fabricados y comercializados, sin embargo, se recomienda implementar una metodología de entrenamiento y capacitación para reafirmar la información allí consignada.

Posterior a la aplicación del sistema de franquicias de la empresa productora pan de arroz se debe analizar si en efecto la franquicia de producción es la más acorde a su organización o puede replantear el sistema para otorgar nuevas franquicias de tipo industrial, en las cuales los franquiciados elaboren todos los productos de la compañía, lo que indicaría la modificación del manual operativo y la documentación contractual.

\section{REFERENCIAS BIBLIOGRÁFICAS}

1. Alcázar, E. 2011. Circular Oferta de Franquicia. (31 de Enero). Obtenido de Entrepreneur: Disponible: https://www.entrepreneur.com/article/263976

2. Amorocho J. 2019. Franquicias esperan volver a llegar a dos dígitos en este año. entrevista con Luis Felipe Jaramillo Lema, vicepresidente internacional de Colfranquicias y director de la Feria Internacional de Negocios y Franquicias, publicado en El Colombiano el 5 de febrero. Disponible: https://www.elcolombiano.com/negocios/franquicias-esperan-volver-a-llegar-ados-digitos-en-este-ano-LF10158276 
3. Arredondo, J. 2003. Los Sistemas de Franquicias y el Fenómeno Emprendedor". En: Debates IESA, 9 (1): 28-29.

4. Cámara de Comercio (CC). 1971. Código de Comercio de Colombia, Decreto 410 de 1971, $435 \quad$ p. Disponible: https://arrincondelparque.com/images/documentos/codigo-comercio.pdf

5. Cámara de Comercio de Bogotá (CCB). 2017. Aspectos a tener en cuenta al comprar o vender una franquicia. Disponible: https://www.ccb.org.co/Sala-deprensa/Noticias-sector-Agricola-y-Agroindustrial/Noticias-2017/Aspectos-a-teneren-cuenta-al-comprar-o-vender-una-franquicia

6. Comisión de Promoción del Perú para la Exportación y el Turismo (PROMPERÚ). 2012. Guía para la elaboración de manuales de franquicias 312 p. Disponible: http://www.siicex.gob.pe/siicex/resources/sectoresproductivos/Gu\%C3\%ADa\%20p ara\%20la\%20Elaboraci\%C3\%B3n\%20de\%20Manuales\%20de\%20Franquicias.pd $\underline{f}$

7. Confederación de Empresarios de Andalucía. La franquicia en la creación de empresas. [En línea]. Sevilla, España, jun. 2016. Disponible en: https://musashi.es/wp-content/docs/franquicia-empresas.pdf

8. Consulta expertos en franquicias (CEF). Como franquiciar un negocio. [En línea]. Madrid, España. [Consultado 03 agosto 2018]. Disponible en: http://www.consultafranquicias.es/como-franquiciar-un-negocio/

9. Forero, J. 2012. Desarrollo de la franquicia en el departamento del Meta. En: Estrategias, 10 (20): 10-15.

10. Gobernación del Meta. 2016. El pan de arroz podría ser incluido en la lista de patrimonio inmaterial de la Nación. Boletín de prensa No. 1000 [en línea] Disponible en: http://www.meta.gov.co/web/blog/el-pan-de-arroz-podr\%C3\%ADa-ser-incluidoen-la-lista-de-patrimonio-inmaterial-de-la-naci\%C3\%B3n

11. ICONTEC Internacional. Norma Técnica Colombiana (NTC) 5813. 2010. franquicias. requisitos generales para la etapa precontractual, contractual y postcontractual de una franquicia. 13 p. Disponible en: https://docplayer.es/9764054-Norma-tecnica-colombiana-5813.html

12. ICONTEC. Norma técnica Colombiana (NTC)- ISO 9001. 2015. Sistemas de gestión de la calidad- requisitos. 47 p. Disponible en: https://escuelajudicial.ramajudicial.gov.co/sites/default/files/NORMA ISO9001 20 15.pdf

13. Instituto Colombiano de Normas Técnicas y Certificación (ICONTEC). Franquicias. Requisitos generales para la etapa precontractual, contractual y pos contractual de una franquicia. NTC 5613. Bogotá D.C. 2015.

14. Jaramillo L. 2016. Más del $90 \%$ de negocios franquiciados sobreviven por encima de 5 años. Revista Dinero., publicado 10 de noviembre. Disponible en: https://www.dinero.com/empresas/articulo/el-negocio-de-las-franquicias-en-elongreso-del-comercio-detallista/234723

15. Jaramillo L. Colombia. 2018. Tercer mercado mundial para franquicias Portafolio julio 08. Disponible en: https://www.portafolio.co/negocios/colombia-tercermercado-mundial-para-franquicias-518854

16. Loaiza L. 2012. Panorama del contrato de franquicia en Colombia: entre las estipulaciones contractuales, el código de ética y la norma técnica. Trabajo de grado abogado. Santiago de Cali: Universidad ICESI. Facultad de derecho y ciencias sociales, 42 p. $\quad$ Disponible 
https://repository.icesi.edu.co/biblioteca digital/bitstream/10906/77604/1/loaiza co ntrato franquicia 2013.pdf

17. Ministro de Salud y Protección Social (MSPS). 2013. Resolución 00002674, por la cual se establece los requisitos y condiciones bajo las cuales el Instituto Nacional de Vigilancia de Medicamentos y Alimentos -INVIMA, como autoridad sanitaria del orden nacional, deberá expedir los registros, permisos o notificaciones sanitarias. 37 p. Disponible en: https://www.minsalud.gov.co/sites/rid/Lists/BibliotecaDigital/RIDE/DE/DIJ/resolucio n-2674-de-2013.pdf

18. Ministro de Salud y Protección Social (MSPS). 2015. Resolución 00000719, por la cual se establece la clasificación de alimentos para consumo humano de acuerdo con el riesgo en salud pública, 20 p. Disponible en: https://paginaweb.invima.gov.co/images/pdf/documentos tramite/Alimentos/Resol ucion 719 PDF.pdf

19. Mosquera, F. 2010. La franquicia: Una estrategia de crecimiento empresarial. Revista MBA EAFIT, 70-85. Disponible en: http://www.eafit.edu.co/revistas/revistamba/Documents/franquicia-estrategiacrecimiento-empresarial.pdf

20. Otero M, Giraldo W, Barbosa J. 2017. Estudio cualitativo para el desarrollo de la marca del pan de arroz. Revista Luciérnaga / Comunicación, 18: 77-80.

21. Pierre S, Rebolledo, C. 2003 La franquicia en Colombia, teorías, realidades y perspectivas. Bogotá D.C. Grupo editorial Norma. p 19-31.

22. Ramírez A. 2017. Identificación de un modelo de franquicia de la marca de Hamburguesas del Oeste y el plan de mercadeo para su comercialización. Proyecto para optar título de Magister, Universidad EAFIT Escuela de Administración Maestría en Administración de Negocios - MBA Medellín. 82 p. Disponible: https://repository.eafit.edu.co/bitstream/handle/10784/11929/GuillermoAndres Ra mirezMartinez 2017. pdf? sequence $=2 \&$ isAllowed $=y$

23. Restrepo L, Barrera C. 2018. Desarrollo de las franquicias en Colombia. Trabajo de grado para aplicar por el título de Tecnólogo en Gestiona de Comercio Exterior y Logística. Facultad de Administración Tecnológica de Antioquia Medellín. 90 p. Disponible en: https://dspace.tdea.edu.co/bitstream/tda/355/1/DESARROLLO\%20DE\%20LAS\%2 OFRANQUICIAS\%20EN\%20COLOMBIA.pdf

24. Rodríguez M, Mora N. 2013. K-LISTO: Franquicia como una estrategia de expansión, Trabajo de grado, Universidad Colegio Mayor de Nuestra Señora del Rosario, Facultad de Administración, 101 p. Disponible en: https://repository.urosario.edu.co/bitstream/handle/10336/4580/RodriguezBenitezMariaCamila-2013. pdf?sequence $=1$ \&isAllowed $=y$

25. Silva J. 2003. "Franquicia. Una Alternativa para Emprendedores". Revista EAN. Número 47: 116-121. Disponible en: https://journal.universidadean.edu.co/index.php/Revista/article/view/239 